\title{
Autonomous participation. An activist ethnography in Maranya Youth Club
}

\author{
Arecia Aguirre, aaguirre@uji.es, \\ +34964729807, orcid.org/0000-0002-1004-8046 (corresponding author) \\ Lidón Moliner, mmoliner@uji.es, \\ +34964729806, orcid.org/0000-0003-0143-898X \\ Joan A. Traver, jtraver@uji.es, \\ +34964729801, orcid.org/0000-0002-5948-1035 \\ Department of Pedagogy and Didactics of Social Sciences, Language and Literature, \\ Universitat Jaume I, Castellón de la Plana, Spain
}

Avd. Vicent Sos Baynat s/n, 12071 Castellón de la Plana, Spain 


\title{
Autonomous participation. An activist ethnography in Maranya Youth Club
}

\begin{abstract}
In this article there is a discussion about the results of an activist Ethnography carried out in Benicasim (Spain). The study is focused on the culture of youth participation in leisure spaces that contribute significantly to the education of young people as critical citizens. During 3 years of fieldwork as an activist in the Youth Club we carried out an investigation based on biographical, narrative, participatory and observational tools. Particularly, we try to understand which elements can turn a participatory structure into a tool for a model of participatory progression and offer the possibility of creating personalized participatory trajectories. Our results suggest that structuring participation in a youth club can be beneficial if we care for aspects like commitment, responsibility, availability, leadership and the sense of membership. Adapting these elements to the characteristics of each youth will boost participation to more autonomous levels, thus enabling an empowering and autonomous learning process.
\end{abstract}

Keywords: Critical Ethnography, Participation, Democracy, Non-Formal Education, Association, Youth Club.

\section{Introduction}

Young people vary over time according to different societies. Hence, the concept of youth is mainly cultural and historically specific and not only can we place it in a biological category (Jones 2010). While a biological familiarization can guide our early notions about youth, it soon becomes clear that youth concept is better view with in a socio-cultural context, not just a particular age range (Lowicki and Pilsbury 2000). If we did so, we would limit our understanding of their lived experiences (Driscoll 2002).

Tyskå and Côté (2015) explain that 'there is a need to develop ways of talking about young people that do not assume youth is merely an "in-between stage" or a "process of becoming", but a form of personhood requiring research in its own right' (593). The definition of youth is compounded, we need studies that allow us to understand this social and historical category from the experiences of young people in a better way. 
So, we commit ourselves with these considerations and we approach the investigation exploring the experiences of youth from their multiple experiences and learning without the assumption that all young people have the same needs and experiences biologically limited.

Youth are ready to construct with their own hands, take decisions autonomously (Kiilakoski and Kivijärvi 2015). This is the way numerous experiences of self-management prove it in cultural institutions in Europe and youth movements worldwide with very important mottos for environmental support, freedom of speech, LGBT, among others. An autonomous youth could be necessary to balance social structures and other differences and inequalities that have influence in individual choices. In participation line of this research we aspire to know how the relation between that autonomy and freedom could mark the young people own personal trajectory and that it can be achieved from their own participatory self-enhancement. Leisure time can be a great opportunity to stimulate these movements and develop participation habits among youth, as well as transmit values of coexistence, sociability and positive leadership (Walker and Saito 2011; Cassels, Post, and Nestor 2015). The concept of leisure time has been defined in different ways. In more particular way for us, researchers (Kuykendall, Boemerman, and Ze Zhu 2018) distinguish leisure engagement (also called leisure participation) in two ways: residual and experiential definitions of leisure (Haworth and Veal 2004). Residual definitions define leisure as all activities other than paid work or other obligatory activities (Roberts 2006). In contrast, experiential definitions of leisure are exemplified in Neulinger's (1981) work on pure leisure, which defines pure leisure as activities that are freely chosen and intrinsically motivated.

Leisure is a promising tool to create socially accommodating environments of affiliation, autonomy and compromise for this population (Kuykendall, Boemerman, and Ze Zhu 2018). From all this arises Leisure Pedagogy that aims to enhance the educational value of leisure. With it constructive and creative attitudes in leisure are generated favoring the formation of active and critical citizens able to transforming their own communities.

Hence Non-formal education can be useful to attain this objective and design project-based leisure spaces with youth where participants find a career in acquiring and expressing a combination of its special skills, knowledge, and experience (Stebbins 2007).

Úcar (2008) presents that youth can end up being moments of exclusion, underestimation or paternalism. Because of that he recommends think about youth as full right partners rather than people who are not adults yet. In numerous papers researchers declare it is fundamental to work and break stereotypes of leadership and promote independence in the 
participation of youth (Hersey and Blanchard 1998) to get non-formal spaces of leisure for young people become spaces of youth voices.

We know participation is useful, it generates community ties, it strengthens and generates learning (Hersey and Blanchard 1998). In this regard we need to explore and reinforce social organization forms that promote the reconstruction of bonds, the formation of collective sense of belonging that are respectful with individual autonomy (and one's own participatory self-enhancement). Lave and Wenger (1991) defend that learning is an integral part of our daily lives. These authors focus on the importance of learning in the process and in active participation in collective activities because knowledge is built interacting with other people and with the environment as learning becomes richer with shared experience. Likewise, they say the most transforming learning is the one that refers to the attachment to a community, to that feeling of belonging to a group, an organization or space because it will be the way in which we will be able to immerse in real situated learning.

Youth associations can be one of them as on one hand, they educate for democracy and on the other promote the active exercise of democracy facilitating the transition from a culture of individualism to a collaborative one that generates participation (Cornejo, González, and Caldichoury 2007).

\section{Methods}

\section{A club for the people: Maranya Youth Club.}

Maranya Youth Club belongs to the Valencian Federation YC which aims to build a network of YCs in the region, promoting the principle of subsidiarity. The underlying premise of this principle is that citizens, not the government administration, should take on everything they are willing and able to manage. In that net the only one that does not belong to the public administration, that is working with volunteers and that is self-financed by its members is Maranya YC. That was one of the most important peculiarities to select it to this study.

Maranya $\mathrm{YC}$ is a public service, a tool to introduce Social participation in Young people and to generate social awareness. Their objective is promoted Young leisure with plural, educative, democratic and secular projects. Currently there are 124 members that participate whether it is with financial contribution, with their voluntary participation in the center management and/or assistance in activities. Mainly, the $\mathrm{YC}$ is supported by financial contribution from members and donations from outsiders. There is not a standard socioeconomic level among the participants, as most of them are working families with a 
medium and high education level. We can say that a very high number are families from Benicàssim that prefer public education.

For the last 5 years they have offered a space that is self-managed and independent from the town council. The structure main feature is that those who participate in the center are organized in stable groups where they channel their likes and interests. This is the fundamental base and from that they shape the structure of participation that is constituted by the following teams that go from lower to higher levels of participation and management that is carried out in the $\mathrm{YC}^{1}$.

\section{[Figure 1 near here]}

Figure 1. Structure of participation.

This structure allows each young person to participate in the house in the function of their approach, opportunities and willing to participate because not everyone have the same situation to make possible the same participation.

\section{Investigating the day-to-day}

The objective of this paper is to investigate what elements define the participation structure of Maranya Youth Club to achieve participatory self-enhancement among youth and analyze how they promote personal and autonomous self-enhancement participation trajectories.

Literature tells us that we cannot address research in a space like this without getting involved or not taking part in the context. Hesse-Biber and Piatelli (2012) talk about negotiating our positions and accepting the changes that will take place in them. In this research, VYT feels that an outsider person that only watches what is happening there without actively participating in the group distorts the context and the action of the YC. For them, the only fact of observing

\footnotetext{
${ }^{1}$ A quickly description of that structure (figure 1) is the next one: Volunteer Youth Worker Team
} (VYT): Are the qualified people as youth workers. Stable groups activists and directors board: They are the ones that lead specific activity groups in the YC and also some are members of management. Stable group members: Young people who are part of the activity groups assisting frequently. Activity users: they assist regularly to courses and services offered by the YC. Activity Consumers: people who participate occasionally in the YC massive activities. 
reality without participating placed me in a 'higher' role. They understood that being part of the group would favor horizontality. Assuming an observer role would lead them to pretend and not act in a natural way because someone was observing them. Therefore, the group requests the researcher becoming the phenomenon she studies (Jorgensen 1989). The demand of the group was not to feel observed but that an equal participates with them in describing their reality and analyzing it critically.

Bernard (2011) talks about participation observation, reduces the problem of 'reactivity' of people changing their behavior when they know that they are being studied. In sum, lower reactivity means higher validity of data.

After the literature revision about participant observation and activist research we decide to define this strategy as activist observation. In an activist researcher role, you are not only a participant in the context activities instead of this you cause and plan actions with the rest of the group. In the participant observation you cannot consider yourself part of and in the activist observation you are part of. Observing in this way, as an equal, makes you understand more closely what happens and the reasons why actions are carried out, among other things.

Bernard explains that in this kind of research it is usually best to start at the top and work down (Figure 1). Because of that the researcher work with VYT to see explicit awareness of the little details in YC life (Spradley 1980).

For someone that could be a problem to objectivity but we consider that objectivity does not mean value neutrality. In one hand, the researcher is part of the community. In the other one, we can't rid ourselves of our experiences, and we don't know anyone who thinks it would be a good idea even to try. We can, however, become aware of our experiences, our opinions, our values (Bernard 2011). With this type of research, we adopt the uncertainty that Lather (2007) talks about, the one that makes us question and problematize each action, opening the possibility that new understandings will appear. Assuming, in turn, the unpredictable nature of this type of research without losing weight to our responsibility (Maxey 1999).

To maintain your objective and analytic abilities Jorgensen (1989) suggests finding a colleague with whom you can talk things over regularly. In that way borns the Advisory committee $(\mathrm{AC})$ with whom we realize our collaborative research (see more in working tools section). Moreover, I plan bimonthly appointments with two university colleagues (the same ones that participate in the AC as university advisors) with whom revise each step I did and with whom I'm writing this article now. They generated a balance in the research between my activist and my research role. That, give myself an outlet for discussing the theoretical, methodological, and emotional issues that inevitably come up in full participation field 
research. In addition to regulate the collection and interpretation of data. Pillow (2003) proposes that this monitoring from within helps us to reflect on the contradictions, difficulties and situations not always comfortable that an investigation of these characteristics entails. In that sense I will be part of the VYT and I organized the AC along the research.

Accordingly, we present all the design and the required process of investigation from a critical approach (Thomas 1993; Madison 2012; Smith 2015; Miled 2017) and activist (Speed 2006; Sukatis and Graeber 2007; Sutherland 2012; Craven and Davis 2013) from which we assume the commitment of putting into operation an ethnography that is close to the context of study, diverse with regard to the tools used and socially committed to change, educational improvement and the fight for a better world (Horn 2004; Kincheloe 2008).

\section{Working tools}

All through this investigation, we used many tools and strategies to meet the criteria of scientific rigour (Lincoln and Guba 1985). One of the basic ones was multiple triangulation in which we will contrast the data coming from different information sources like the techniques used, the constructed tools (table 1) and the voices of the involved participants.

[Table 1 near here]

Table 1. Working tools.

The ethnography is carried out during three years of activist engagement in Maranya $\mathrm{YC}$ where it is known and recognized at all times that an investigation is carried out about the culture of participation that the YC promotes. From 2014 to 2016 it's when the researcher was involvement on the VYT of the YC as youth worker. From this team is from which the researcher makes the activist observation (field diary).

Concurrently borns the AC. The creation of an AC was constituted by the YC participants, people who are external to the association but linked to the youth club's movement and researchers in the area of education. That has been a fundamental aspect to make this research collaborative. Together we work, contrast and build up all the information that shapes this research. As well as, an inside triangulation of researchers is carried out that is controlled by the colleagues in the AC that will avoid distortion between the role of the activist and that of the researcher. Objectivity is sought in this research, therefore the methods of data collection and interpretation of the data is always worked, valued and modified by the AC.

$\mathrm{AC}$ is the group of data interpreters that have a direct connection with the youth movement that will translate the information in a reliable and credible manner (Ratcliffe 1983). They play an important role in data triangulation giving coherence to the gathered information. 
Thus, the necessary coherence is granted to the research in order to consolidate the thoroughness standards necessary in qualitative research.

Another of the basic tools was the interviews, designed by the AC. The interviews have been addressed from the plurality of voices through participation of a cross section of the context structure, which gave the data neutrality, consistency and credibility (Table 2). These are focused on the definition and meaning of Maranya $Y C$ for the participants, personal experience, participation and generated learning, meaning of public space, type of external communication and other issues that came up in the interviews like the relationship with the community.

[Table 2 near here]

Table 2. Groups and interviewers.

Finally, following Atkinson (1997) and Moriña (2016), we have decided to go for several types of analysis that will help us understand the narratives, structure the story and fully understand its complexity. To do that we will carry out a structural analysis (Miles and Huberman 1994; Braun and Clarke 2006), followed by a narrative analysis (Atkinson 1997; Bochner 2001; Moriña 2016) and ending with a critical analysis. This type of analysis allows a construction of Maranya YC Life History from different angles.

In the following section of results, we will extract verbatim of this history that coincide with the categories (commitment, responsibility, availability, leadership) analyzed in this article that define the current participation structure in Maranya $Y C$.

\section{Autonomous construction: structures and participatory self-enhancement.}

The structure of an association is important to know how they organize participation to attain the established objectives and thus understand what actions will be performed to achieve them. The structural management of participation in Maranya YC is based on a specific model, the participation models of YCs in Zaragoza that elaborate a unique system that differentiates the degree of participation according to participative self-enhancement of people. The Valencian Federation of Youth Clubs where Maranya YC belongs promote this model.

Although it may seem this hierarchic participation structure refers to a gradation of authority, it is really structured like this to facilitate a personal participatory trajectory as an educational and democratic process as we could see then with the explanation of the four variables (commitment, responsibility, availability, leadership). 
Thus, we can see it in the trajectories of different young people of the $\mathrm{YC}$ or in the future wishes of new members of the Esplai:

'Lydia and Ivan are two of the young who have been in the YC the longest. Both have been part of the project since the birth of Esplai Cataflai. When this happened, a part of them grew up that they now recognize as essential in their lives. Ivan is now fifteen years old and is studying at High School. Lydia is one year older than he goes to the same High school and both are part of the stable group Perduts pel món. They have been together since they were very young, they remember that when they were seven years old they already joined Esplai and they did it by the contagion of other children who were already part of the group. A friend told Ivan and mothers were convinced to go that same year. It was 2006 and Esplai Cataflai was consolidated as a stable group within the YC. Lydia arrived a year later, she started going because Ivan convinced her. They both liked the experience and little by little the implication was getting bigger and bigger until they joined the theatre group because they no longer felt so small as to continue in Esplai. The story of the two is very characteristic because they go from being child of Esplai Cataflai to being part of the team of monitors of Esplai today. Lydia and Ivan relate it as a whole cycle they have achieved' (verbatim p.48, GI 003.01.03-04Act).

\footnotetext{
'Aina keeps shaking her head, reaffirming everything her mother says. She is eight years old and loves camping and making new friends, but especially when she is older she wants to be like Lydia, the new Esplai monitor'. (verbatim p.93, II 001.01AU).
}

This adaptation has been studied for years at school and it showed that adapting space to the needs of people favors learning (Duke and Hinzen 2009; Moriña 2008). That way offers the opportunity to create different trajectory when young people will have different approach, opportunities and willing to participate. One of the aspects to consider in this analysis is that there are no found data among age and participation. Although we would like to address this issue more broadly in other research, we have observed that participation depends more on the relevance of the four variables and the level that it takes place in the personal characteristics of young people than on their age. The only case in which it interferes the age with the participation is because Spanish law require that a youth worker has a labor certification and more than 18 years old. Because of that people who participates on the VYT have to be more than 18.

So, we will address below the four variables that affect participatory self-enhancement and offer the opportunity to design diverse participatory trajectories through commitment, responsibility, availability and leadership of people. 
These variables can be understood as the capacities that Sen (2001) tells us about, understood as the opportunities to choose and carry one kind of life or another. Increasing these human capacities must be an important part of the promotion of individual freedom. This approach provides us with a theory of freedom and its exercise is at the base of social commitment. In this sense, he tells us that freedom understood in a positive sense (be free to choose) refers to what a person can really accomplish considering all the factors that surround it. The opposite, the negative conception (being free of something) is concentrated precisely in the absence of limitations that a person can impose on others. In this particular research, we understand this commitment as defined by Sen when he talks about it.

In commitment we see how the involvement of people can be measured, their effort for being there and be a part of the place and their capacity to become aware of the importance of their participation. In this way, in this particular research, depending on the level where one person is in the hierarchy, they will not be as committed in the same way to the objectives of the YC. For example, one person that goes to the club for a specific service, like attending the annual Halloween party, will not be as committed as a youth worker of a stable group that takes part in the design and organization of the group's direct action. These differences are increased in some characteristics of the $\mathrm{YC}$ :

\footnotetext{
'Youths in Maranya YC have to learn to militate, to maintain a space that is their own and that costs money unlike the rest of Clubs that are supported by the government. These Clubs can exist and focus their effort on other matters but here the major headache is how to have financial solvency to take activities forward, pay for the premises, water, electricity and gas bills, and even not run out of toilet paper. That's why management can be different if we compare it with other Clubs and the compromise has to be stronger and with a greater burden of responsibility' (verbatim p.103, GI 003.04.01FG).
}

We see that the four variables are interrelated, as responsibility could be a key factor within commitment. We see how you can find yourself at the same time in one level of responsibility or other. Depending on that aspect, you will assume a type of commitment with the association.

\footnotetext{
'You have to feel the responsibility of being here and it shouldn't be another person but you the one telling yourself you have to take responsibility. This change of perception makes some people take on work in various ways' (Verbatim p.102, II002.10FA).
} 
Concerning this variable, it is interesting to investigate how depending on the perception people have about the $\mathrm{YC}$, it gains or loses strength. The reason for it originates when responsibilities are perceived as an obligation, they lose interest and stop feeling the responsibilities as their own. In these cases, they have either abandoned the YC, they have distanced themselves from the group or the group ceased to exist.

\begin{abstract}
'Some people that have been an activist part in the club explain that you must keep clear in your mind that you want to belong, you have to be ready to invest your time in it because it requires a lot of time and work to carry your task forward. The difficulty comes when this responsibility is taken as an obligation and not like something voluntary that you do with a different objective. Considering it like an obligation and not feeling comfortable with what you do is the moment that makes you see you're not there anymore because you want but something has changed and this hobby turned into an obligation' (Verbatim, p.108, GI03.01FA).
\end{abstract}

When they feel the pressure and start being disenchanted by tasks that were exciting before, the outcome has always been the person's detachment from the group. 'What is owed lies in the recognition of a bond, of a ligatio, from which an ob-ligatio (ob-ligation) arises, and this obligation can be either a duty, that is the ob-ligatio, as a response to a demand or a gift given by whoever knows and feels bonded to someone else. Without the bond being recognized, the duty or gift are meaningless' (Cortina 2007).

'This person has understood that in order not to consider it a burden one has to be aware of their own limitations and the group's. He explains that it should be understood in volunteerism matters: involvement varies from person to person although it is true that a minimum amount of commitment will be necessary so everything works. He says each person gets involved to the desired extent and that recognition will stop forced situations when there are tensions and according to Joana, it won't end up being an emotional burden for people. To improve it, he says it is essential to carry out an analysis of the internal and external limitations and the potential you can offer to the group' (Verbatim, p.73, II002.10FA).

The way we see the duty can be understood in different ways and depending on how the bond recognition is worked, duty can be perceived in a different way. This can be related to the different levels of commitment that each person decides to have and the lack of understanding among the rest.

'There came the moment when, as a group we had shouldered a bigger burden than we could carry in general, not only in Maranya YC, but at a personal level. I think our mistake, so to 
speak, was not being aware that we were a group of six people that had mental and physical limitations and wanting to do so much made us get so burned out that we reached a point that we couldn't say "hey, let's fix that", but it was a "hey, I can't deal with this anymore". In fact I was one of the first to leave the group because I was living in Valencia, working in Vila real (1 hour commute), and spending also time in Benicasim, so I was quite overwhelmed and precisely that's what, according to me, put an end to the group: not having been aware of our limitations' (Verbatim, p.74, II002.10FA).

Perceptions change depending on the person and that may affect to a greater or lesser extent depending on the existing spaces to share those perceptions. For this reason, focusing on the learning associated to it, we have to be concerned more about the process that is carried out so a person recognizes a task as a duty or as a gift and worry less about the number of responsibilities they have in a group, because its stability through time will depend on that. So, the interesting aspect is to obtain, no matter how, participation wherein youth takes part in the development process and that is a guarantee that the protagonists will find the organization methods that work most effectively in their context and needs (Cornejo, González and Caldichoury 2007) and work the concepts of commitment and responsibility in the educational context. In sum, a more effective process of participation where a young people direct action would be possible.

'Young people also admit that they have learnt to take responsibilities in the club. Well, "they are not responsibilities but the most ethical way to teach another person what you know" (II002.03AU). Feeling useful, feeling they can help others encourages them to continue working in the projects of Maranya YC. Many end up describing their trajectory in the Club as a vital learning process. All coincide, youth and adult, that is a constant learning: learning of experiences and theoretical learning that you can put into practice in your daily life. They apply everything they have learnt to their life outside the association because the association is life in itself and that pushes them to analyze the benefits of belonging to the group' (Verbatim p.94, MO001.01FD; II002.03AU).

Willis (1998) also notices this idea when he describes the capacity that young people have when they get involved in cultural practices that haven't been imposed, but have been built thanks to their autonomy and based on their own interests. Kiilakoski and Kivijärvi (2015) also emphasize it because they see that when youth have the possibility of taking decisions and managing their function in youth clubs, they obtain better educational outcomes. 
'In the Youth Club a powerful movement was being forged. To that moment there were activities, workshops, excursions, training and three stable groups: Espai Cataflai giving leisure time of boys and girls dynamism through an education in values with community-based working methods; a drama group called Estem Vius (We are Alive) that vindicated through art and Quatre Gats that programmed alternative and attractive evening activities for the young people in town' (Verbatim p.40, MO001.02FD; WD016.01).

That is why, as they analyze in HEBE project (Soler 2015) we precisely need new forms and structures of youth participation that emerge from youth themselves and are created from their own principles and needs. These structures have an internal defined and sustained organization that can coexist with the structures created for the political representative democracy.

Another variable that affects the process of participative maturation is availability. Time is a highly valued factor nowadays, citizens are trapped in their individual time and forget about the global aspect and that has repercussions in the social commitment that could be assumed in collective spaces. For this reason, depending on the individual sphere of each person and the commitment they assume to society, they will have more or less time available to dedicate to collective projects. This is the way it is analyzed in Maranya YC's history.

There are different levels of availability and they depend on the level of participation of people in the Club which affects participatory trajectory of each young. Many youths are blocked by academic requirements and this is one of the factors that influence their perception of time. We would like to focus on that for future proposals of reality analysis as we consider it is a very important factor, the analysis of time in leisure pedagogy.

Furthermore, relating to participatory progression we find its connection with leadership that is exercised in the YC as it affects the roles that participants take on. We see that when youths that have been characterized by their capacity to lead, coordinate and influence the group, they have gone from users to active members of a stable group and even join the VYT. For this reason, the leadership exercised affects the participatory trajectory of the person somehow or other. Besides, depending on the type of leadership exercised, it will affect the stability and the educational project of the Club differently (Guibert 2011).

'It all comes from a group of people that has always been there and thanks to them, Maranya $\mathrm{YC}$ is alive today. Others have been changing for personal matters, some years they had more availability and others not so much. But it is clear that if the group of people that constituted 
the VYT didn't exist, and if mainly Virginia and Victor2 weren't there, Maranya YC would no longer exist today. And this is something with which all the participants in the Club I interviewed agreed. There's a powerful group of people that coordinate and manage Maranya YC and thanks to their trajectory and their assimilation of the youth club model, work in a very structured and systematic form. On the other side, we find the side that maybe hasn't assimilated the model as much or they do from a different perspective' (Verbatim p.105, MO001.02FD, GI003.01.03Act.).

All this can be exemplified with the role of the VYT in all this process. First of all, we find the VYT on top of the pyramid, and they are, according to the YC Model, the object of higher participatory progression. That's why the type of leadership exercised by the ones that constitute it will influence the participatory trajectory of the rest of members of the Club as participation increases leadership abilities (Walker and Saito 2011) and for this reason we have to analyze and reflect on the type of leadership we show because it influences the work of some principles or others (Cassels, Post, and Nestor 2015). Besides, history shows there are significant differences in the participation of people that constitute the VYT.

\begin{abstract}
'A great deal of the weight of the association is carried by two people mainly: Virginia and Victor. Both have experience, an established working method and a very strong militancy with Maranya YC. There are youth that do assume leadership but this leadership, according to them two, doesn't agree to their age, but they should be doing other things. The rest of animators of the VYT very often compare volunteerism with work and that weakens them. As it's not assumed the same way, compromise varies and implications too. If you come to a session of the VYT you'll see it's always similar: they lead and the rest usually accept what they propose. Some people participate more in the work but it's quite common that they watch from the sidelines. We are speaking about a group of six people in which the group assumes that both are the main pillars of activation of Maranya YC for the moment. Despite that, they never miss an opportunity to insist that they are a team, which is bigger and bigger and everybody is essential' (Verbatim p.105, GI003.02.02VYT).
\end{abstract}

Some take on the role of coordinators and others prefer to take on a learning role. Half way we find the ones who manage projects with the help of coordinators. I'm going to focus on the specific analysis of this participation because the VYT is in charge or carrying out the educational project of the center apart from being a model for the rest of structures of the Club.

\footnotetext{
${ }^{2}$ Victor and Virginia are the first youth workers that have Maranya YC.
} 
Let's say the same way the YC is structured into a pyramid that is divided into 5 stages, the VYT is also constituted by different stages according to the participatory progression of its members: youth worker coordinators of VYT, volunteer monitors of projects and team apprentices

A factor that can influence this distribution is mutual trust that exists in the group as the group identifies with their leaders even though sometimes it creates a dependency of the rest of the team on coordinators.

\footnotetext{
'The people that constitute the VYT are not selected by the group but they have belonged to the group for many years and have established as essential figures in the club. This generates a dependency towards them because they lead the project, apart from a possible overburden in the VYT as it results in not everybody participating in the club or even the VYT in particular, to know the positions, functions and tasks of each one. These places should generate autonomy feelings instead of dependency ones. They should invalidate the feelings of not knowing how to do things well and accept on the animators' side that if a person does something in a different way the animator would do, they can learn from it if they fail later. Sometimes the attitude is hard because animators feel this step should have already taken place. They shouldn't take the educator-monitor role but all the educators should have equal responsibilities, but this step is not happening yet' (Verbatim p.106, MO001.01FD, MO001.02FD).
}

It is unknown if the YC would work the same without leadership, with different leaders or if they didn't exist. What we know is that guidance, in many occasions, turns into management and that can influence the maturation of people to assume responsibilities in the YC. Coordinators have very consolidated ideas of the YC Model and of the project they want for Maranya YC. If we add to that their communication skills, it makes it simpler to work towards a specific model of action. They think they know what path to follow to exponentially increase participation and those are the steps they want to take. However, it has to be considered that an element that poses a difficulty in participation is the difficulty to break these stereotypes and roles assumed traditionally and that each social actor takes on. If we can't break them in the learning process we will find dependence between the different participants that can influence the achievement of generational replacement that the coordinating team expects.

Hersey and Blanchard (1977) say that depending on the maturity, shaped by the will and capability of the group, the leader has to behave in a different way going through stages of management, persuasion, participation or delegation. The VYT, rather than being a type of leader, takes on a different role depending on the situation like all these authors say. This choice questions the values that are embedded in the Club like dialogue, horizontality, collective 
decision-making, sharing objectives, trust and mutual recognition and joint planning, among other aspects.

For this reason, we have to take into account that the type of leadership that is exercised is going to influence the individual and collective growth apart from working as a model for learning in the Club. Therefore, we need to rethink the choice towards a model of distributed leadership (Gronn 2002; Timperley 2005) that facilitates community work and makes it possible that all the VYT turns into a change agent inside the organization. Achieving it doesn't only depend on the change in task distribution but needs a change in the culture of the group (Murillo 2006) suggesting spaces for dialogue, horizontality and collective decision-making.

\footnotetext{
'All the members of the center participate in it and although all the people who participate have a right to make proposals and actions, always in a reasoned manner, the only people that have a right to vote are youths between 14 and 30 years old. The rest have a voice but no voting rights. This is due to one of the strongest objectives of the Club: giving the youth group a direct leadership in the management of activities' (Verbatim p.99: WD004.07, MO001.01FD).
}

This doesn't happen collectively and horizontally in the VYT when the distribution explained before stands out making the coordinators of the VYT group take the decisions. We cannot neglect that in this type of choice towards a specific leadership style, it is important that the rest of the team is able to value their own potential in their contributions. State full participation will be achieved when whoever constitutes the group are able to play a leading role in this sense. Comparing it with the theories from Hersey and Blanchard (1977) this could make a reference to the maturity of the group they were talking about in a way that the more prominent they get, the more mature they are. There we can see a direct connection with mutual recognition assuming its importance to reach adequate maturity in young people. Let's remember there were youths that didn't feel their work was recognized, but the contrary. If things were not done a certain way they weren't well done. This opens a door of analysis to what would happen if projects and activities were not done the way they have always been done, if they didn't follow the exact same steps people had taken before within the movement. Opening the door to new initiatives and different creativity could strengthen the project with an increased openness sustained by diversity. That, or really making recognition explicit, gives the opportunity to contrast with the different options to share the construction of something new.

In conclusion, we have to improve personalized participatory trajectories, we have to try associations to be the context where we are able to develop practices according to personal interests. We have to set those spaces and also facilitate participants the resources to learn what 
they need with the objective of acting and taking decisions doing it from their own knowledge (Wenger 1999). In this way, participation in Maranya $Y C$ is divided into levels with the idea of generating these spaces in which each person, according to their participatory progression, can act in the corresponding learning process. For this reason, operate on efficiency criteria, prioritize objectives and face the need of a distribution of tasks, must be understood from empathy, respect and above all the search for coherence among the values and methodology but never from tiers of power, authority and/or personalities. That's why we have to walk towards a leadership distributed within all this pyramid structure of participation.

For this reason, the engine of action is not found in obedience but in meaning; people do what they find meaningful. Meaning is a collective product, it is built with significant others. So, in order to obtain full participation in the team, they could consider the objective of guiding participation with the aim that everybody involved has the same opportunity to contribute when building collective knowledge finding meaning in spaces and moments and adapting them to the characteristics of each member. This way they will favor the achievement of individual empowerment based on a progressive scale of participation that eventually leads to something more interesting, the group empowerment from democratic participation and fair dialogue under an argumentative agreement.

In all this process of participatory progression there's an important objective for the YC: Generating generational replacement that is committed, responsible, available and able to lead the space. For this reason, one aspect we haven't dealt with yet is the need to create a generational replacement that permits a change in the VYT.

\footnotetext{
'This relationship among the levels of participation and of leadership affects the objective of generating a generational replacement in the Club. Victor and Virginia and even Julio and Enrique3 explain that there are times when the YC go through phases of four or five years and in these phases, they have to work to get a good generational replacement that supports the work of the Club when the VYT changes. There must always be someone; we have to have people that can take over so Maranya YC doesn't come to an end. Now we have four or five people but in some years, they should be different. That's why it is important that we get new people and that people move so this movement generates the right replacements' (Verbatim p.106, MO001.02FD).
}

\footnotetext{
${ }^{3}$ Julio and Enrique are youth workers and are integrated in the Maranya.
} 
It is one of the main concerns of the VYT coordination and it is something that tries to be worked on from the participation pyramid. Coordinators are concerned because the rest of members don't take charge the way coordinators would like to and there isn't a strong social basis to generate active members that end up being that replacement. With respect to the first question we can stop to think if taking responsibilities comes up naturally or it is imposed, if youths decide to commit from their participatory progression. Also, we have to rethink about how the responsibility taking is addressed. On the other hand, reassess the situation with the group could be one of the solutions as it was done some years ago. Let's remember the same happened in another moment of the history of Maranya $Y C$, when they ask for a replacement in Esplai.

\footnotetext{
'Then an important crisis comes to the group, between the monitors and the families. For some time, there are meetings with boys and girls, families and monitors to find a favorable solution for all the sides, a solution that keeps Cataflai alive. Some families get involved in it and get down to a collective proposal. Espai Cataflai needs support, the families want to roll up their sleeves and collaborate, networking has to be stimulated, union with other centers has to be promoted and strengthen relations in town. A social mapping is carried out in the group with this objective in order to build partnerships with the town. There's a joint-responsibility among families and monitors and fathers and mothers rise up and say 'I'm also collaborating, I'll do sessions if I have to, apart from the role of parent I have now'. When carrying out the mapping they realize they can count on other associations and if there's a hiking center, combine sessions with them and not duplicate activities, and if there's a senior center that can teach any activity, they can also collaborate with them.

Ultimately, there's co-responsibility among all the people that constitute Esplai and basic elements of cooperative learning start to be worked on. During these days of crisis, Esplai got stronger and the relations among families, monitors, girls, boys and surroundings became closer and more complicit. This crisis changed the philosophy of the group giving rise to a more communitarian one' (Verbatim p.40, MO001.02FD, WD004.01).
}

In this case, collective reflection with the families brought a series of options to give an answer to this situation. They found the solution in the possibility of generating connections with the community outside Esplai and involve families, boys and girls more directly in the program and management of the group. This is why we could wonder if it is necessary that the replacement is only generational. Couldn't there be a replacement coming from other places? Maybe those replacements could come from adult groups or from new youth workers that become members of the YC? The approach of the VYT group coordination is to obtain a 
generational replacement that substitutes them from reflection and with their own leadership, when they are not in this space anymore. We should analyze what options could be possible and what are the reasons why it doesn't happen at a generational level.

\section{Conclusion}

The systematization of the model we follow here promotes leadership among youths that little by little transform into activists of stable groups giving shape to the social base of a selfmanaged social center. In this fact one can see how the group of youth assumes a degree of autonomy that is high enough to carry out and strengthen their own initiatives. This influences youth identity consolidating the stable and strong movement of young people that promote their own activities.

We see how a personal participatory trajectory goes from a lower to a higher degree of involvement. This strategy of participatory distribution empowers youth to active participation, reflective and critical thinking and responsible action around relevant matters that affect them (Díaz-Barriga 2003). This way we turn it into an effective, meaningful and motivating participation for the learning of young people.

In this sense a person can start as a member of a group of eventual users, move to being the user of a workshop that constitutes a stable group, then managing it as an activist and end up being an active part of the group of volunteer active members. The analysis shows how oneperson positions in the hierarchy from the learning derived from his/her own participation. On the other hand, this structural strategy makes the volunteer youth worker team (VYT) to know at all times how to organize activities and actions that they propose, to mobilize more some groups or others depending on the needs at that time. It also works as a guide to address activities to some learnings or others depending on its participation. Responsibilities vary depending on the participatory stage where they are so commitments are assumed gradually together with the different learnings. For example, one person who is a member of a stable group will ensure his/her attendance to group sessions and the participation in the group's everyday life. However, a youth worker commits to giving a dynamic edge to the group and for this reason they take on responsibilities like convene meetings and make sure the minutes are written down and are disseminated in the group, among others.

A Youth Club that is created on the basis of a participation structure that looks after the participatory self-enhancement of the people involved generates a process of learning that arises from commitment, responsibility, availability and leadership. This enables personal trajectories 
that favor participatory self-enhancement by means of their participant's learning. That is, they are generating an autonomy that is stable enough to generate your own personal trajectory of participation depending on your participatory self-enhancement.

This strategy of structured participation is essential to the development of a personal trajectory in the improvement of citizen engagement and democratic participation. Having a structure that considers capacities, abilities and the maturity of the people who participate in it and use it to generate a personal participatory trajectory can imply an individual empowerment that strengthens community work.

All these fits with the characteristics described by Stebbins (2007) about serious leisure: need to persevere at the activity, availability of a leisure career, need to put in effort to gain skill and knowledge, realization of various special benefits, unique ethos and social world and an attractive personal and social identity.

Thus, we emphasize the interest in creating educational spaces in all the spheres of life that enable community management. Youth needs new prominence that is built from its own participation. For this reason, it is necessary to emphasize that it is essential that these leisure spaces are built from community management through associative models that work structurally and organizationally with an educational objective and not only for fun. By doing so, youth associations could constitute one of the fundamental pillars in youth education.

\section{References}

Atkinson, Paul. 1997. “Narrative Turn or Blind Alley?” Qualitative Health Research, 7: 325344.

Bernard, Harvey R. 2011. Research Methods in Anthropology: Qualitative and Quantitative Approaches. Lanham, MD: AltaMira Press.

Bochner, Arthur. 2001.“Narratives Virtues.” Qualitative Inquiry, 7: 131-157.

Braun, Virginia and Victoria Clarke. 2006. "Using thematic analysis in psychology." Qualitative Research in Psychology, 3(2): 77-101.

Cassels, Alicia, Liz Post, and Patrick I. Nestor. 2015. "The 4-H club meeting: An essential youth development strategy." Journal of extension, 53(1): 1-7.

Cortina, Adela. 2007. Ética de la razón cordial [Ethics of Social Reason]. Oviedo: Nóbel.

Cornejo, Rodrigo, Juan González and Juan P. Caldichoury. 2007. Participación e incidencia de la sociedad civil en las políticas educativas: el caso chileno [Civil society participation and advocacy in education policies: the Chilean case]. Buenos Aires, Argentina: Fundación Laboratorio de Políticas Públicas. 
Craven, Christa and Dána-Ain Davis. 2013. Feminist activist ethnography: counterpoints to neoliberalism in North America. Lanham: Lexington.

Díaz-Barriga, Frida. 2003. "Cognición situada y estrategias para el aprendizaje significativo" [Situated cognition and strategies for meaningful learning]. Revista electrónica de investigación educativa, 5(2).

Driscoll, Catherine. 2002. Girls: Feminine adolescence in popular culture and cultural theory. New York: Columbia University Press.

Gronn, Peter. 2002. "Distributed leadership as a unit of analysis." The Leadership Quarterly, 13: 423-451.

Guibert, Jose M. 2011. Gestión socialmente responsible [Socially responsible management]. Bilbao: Universidad de Deusto.

Haworth, John T. and A. J. Veal. (Eds.). 2004. Work and leisure. New York, NY: Routledge.

Hersey, Paul. and Kenneth H. Blanchard. 1988. Management of organizational behavior. Englewood: Prentice Hall.

Hesse- Biber, Sharlene Nagy and Deborah Piattelli. 2012. "The feminist practice of holistic reflexivity." In The handbook of feminist research: theory and practice, edited by Sharlene Nagy Hesse- Biber, 557-582. Thousand Oaks, CA: Sage.

Horn, Raymond. 2004. Standards. New York: Peter Lang.

Jones, Gill. 2009. Youth. United Kingdom: Key Concepts.

Kincheloe, Joe. 2008. Knowledge and critical pedagogy. Dordrecht, the Netherlands: Springer.

Kiilakoski, Tomi and Antti Kivijärvi. 2015. "Youth clubs as spaces of non-formal learning: professional idealism meets the spatiality experienced by young people in Finland." Studies in Continuing Education, 37(1): 47-61.

Kuykendall, Lauren, Louis Boemerman and Ze Zhu. 2018. "The importance of leisure for subjective well-being." In Handbook of well-being, edited by E. Diener, S. Oishi, and L. Tay. Salt Lake City, UT: DEF Publishers.

Lather, Patti. 2007. Getting Lost. Feminist Efforts toward a Double(d) Science. Albany NY: SUNY Press.

Lave, Jean and Etienne Wenger. 1991. Situated Learning. Legitimate peripheral participation. New York: Cambridge University Press.

Lincoln, Yvonna. S. and Egon Guba. 1985. Naturalistic inquiry. Beverly Hills, CA: Sage.

Lowicki, Jane and Allison Pilsbury. 2000. "Recognizing War-affected Adolescents: Frameworks for action." Development, 43 (1): 73-82. 
Madison, Soyini. 2012. Critical Ethnography: Method, ethics, and performance. Thousand Oaks, California: Sage.

Maxey, Ian. 1999. "Beyond boundaries? Activism, academia, reflexivity and research.” Area, 31: 199-208.

Miled, Neila. 2017. "Muslim resarcher researching Muslim youth: reflexive notes on critical ethnography, positionality and representation.” Ethnography and Education, 2017:115.

Miles, Matthew. B. and A. Michael Huberman. 1994. Qualitative Data Analysis: An expanded sourcebook. Thousand Oaks, California: Sage.

Moriña, Anabel. 2016. Investigar con historias de vida [Research with life stories]. Madrid: Narcea Ediciones.

Murillo, Francisco J. 2006. "Una Dirección Escolar para el Cambio: del Liderazgo Transformacional al Liderazgo Distribuido" [School Leadership for Change: From Transformational Leadership to Distributed Leadership]. Revista Electrónica Iberoamericana sobre Calidad, Eficacia y Cambio en Educación, 4(4e): 11-24.

Neulinger, John. 1981. The psychology of leisure: Research approaches to the study of leisure. Springfield, IL: Charles C. Thomas.

Pillow, Wanda. 2003. "Confession, Catharsis, or Cure? Rethinking the Uses of Reflexivity as Meth-odological Power in Qualitative Research.” International Journal of Qualitative Studies in Education 16(2): 175-196.

Ratcliffe, John W. 1983. "Notions of validity in qualitative research methodology." Knowledge, Creation, Diffusion, Utilization, 5(2): 147-167.

Roberts, Kenneth. 2006. Leisure in contemporary society (2nd press). Wallingford, UK: Cabi. Sen, Amartya. 2001. Development as freedom. Oxford New York: Oxford University Press.

Smith, John. 2015. "Puncturing notions of precarity through critical educational research on young lives in Australia: towards a critical ethnography of youth." Ethnography and Education, 11, 2: 129-141.

Soler, Pere. 2015. "Proyecto HEBE. El empoderamiento de las jóvenes: análisis de los momentos, espacios y procesos que contribuyen al empoderamiento juvenil." National proyect in Programa Estatal de $R+D+I$ «Retos de la Sociedad 2013», MINECO (EDU2013- 42979-R).

Speed, Shannon. 2006. "Entre la antropología y los derechos humanos. Hacia una investigación activista y comprometida críticamente" [Between anthropology and human rights. Towards Critically Engaged and Activist Research]. Alteridades, 16(31): 73-85. 
Stebbins, Robert A. 2007. Serious leisure: A perspective for our time. New Brunswick, NJ: Transaction.

Sukatis, Stevphen and Davis Graeber. 2007. Constituent imagination: militant investigations, collective theorization. Ak Press: Oakland.

Sutherland, Neil. 2012. "Activist ethnography and social movements: opportunities and potentialities.” In: 7th Ethnography Sumposium, Liverpool, 29-31 August 2012.

Thomas, Jim. 1993. Doing critical ethnography. Newbury Park, California: Sage.

Timperley, Helen. 2005. "Distributed leadership: developing theory from practice." Journal of Curriculum Studies, 37(4): 395-420.

Tyskå, Vappu, and James Côté. 2015. “Toward a non-normative youth studies?” In P. Kelly and A. Kamp (Eds.), A Critical Youth Studies for the 21st Century. Leiden, The Netherlands: Brill.

Úcar, Xavier. 2008. "Factores clave de la participación en los espacios públicos” [Key factors of participation in public spaces]. Animador Sociocultural, Revista iberoamericana, 2(1).

Walker, Kathrin and Rebecca Saito. 2011. "Youth Are Here: Promoting Youth Spaces through Community Mapping." Afterschool Matters (14): 30-39.

Wenger, Etienne. 1999. Communities of Practice. Learning, meaning and identity. Cambridge: Cambridge university press

Willis, Paul. 1998. Cultura viva: Una recerca sobre les activitats culturals dels joves. Barcelona, España: Diputació de Barcelona. 